\title{
Células troncales derivadas del tejido adiposo: Técnica de obtención y utilidad en cirugía*
}

Drs. MANUEL MERUANE N. ${ }^{1}$, MARIANA ROJAS R ${ }^{1}$

1 Departamento de Anatomía y Biología del Desarrollo, Facultad de Medicina, Universidad de Chile, Santiago, Chile.

\begin{abstract}
Adipose derived stem cells: Isolation technique and application on surgery

Human wound healing requires multiple inflammatory cells, cytokines, growth factors and mesenchymal stem cells, which are found in almost all adult tissues, mainly in the bone marrow and adipose tissue. Has been shown multilineage differentiation capacity of these cells and their involvement in other processes by secreting paracrine factors. In the following review will discuss the technique to obtain and cultivate stem cells from liposuction adipose tissue, in addition to reviewing the publications in which they have been used to treat surgical diseases in humans. These include treatment of radiation scars, fractures, anal fistulas, soft tissue augmentation and organ transplantation. Now is included in surgery the concept of "regeneration" in addition to the traditional resection and healing. The results presented are favorable although more randomized studies are required.
\end{abstract}

Key words: Stem cells, adipose tissue, healing.

\section{Resumen}

La cicatrización humana requiere de múltiples células inflamatorias, citoquinas, factores de crecimiento y células troncales mesenquimáticas, las cuales se encuentran en casi todos los tejidos adultos, principalmente en la médula ósea y tejido adiposo. Está demostrada la capacidad de diferenciación multilinaje de estas células, así como su participación en otros procesos al secretar factores paracrinos. En la siguiente revisión expondremos la técnica para obtener y cultivar células troncales desde el tejido adiposo lipoaspirado, además de revisar las publicaciones en las cuales se las ha utilizado para tratar patologías quirúrgicas en humanos. Estas incluyen tratamiento de cicatrices por radiación, fracturas, fístulas perianales, aumento de partes blandas y trasplante de órganos. Se incorpora a la cirugía el concepto de "regeneración" adicional a la tradicional resección y cicatrización. Los resultados presentados son favorables aunque aún faltan más estudios randomizados.

Palabras clave: Célula troncal, tejido adiposo, cicatrización.

* Recibido el 7 de Julio de 2010 y aceptado para publicación el 5 de Agosto de 2010.

Correspondencia: Dr. Manuel Meruane N.

Av. Kennedy 7301 Dpto. D-104, Santiago, Chile.

mmeruane@vtr.net 


\section{Introducción}

Uno de los objetivos fundamentales de la cirugía es restablecer la anatomía y función de órganos o segmentos corporales luego de algún tipo de lesión.

Algunos invertebrados como la planaria pueden regenerar segmentos corporales íntegramente como forma habitual. Anfibios como la salamandra pueden regenerar miembros perdidos a través de un proceso de dediferenciación. En humanos sólo el hígado puede recuperar su tamaño y función inicial luego de una resección ${ }^{1}$, pero el resto de los órganos incluyendo la piel no pueden regenerarse por completo ${ }^{2}$.

El proceso de cicatrización es dinámico e interactivo, intervienen mediadores solubles, células sanguíneas, células mesenquimáticas y matriz extracelular. Consta de 3 fases que se sobreponen en el tiempo; inflamación, proliferación y remodelamiento ${ }^{2}$.

Uno de los hechos más destacables que se ha llegado ha conocer en la última década es que en el proceso de cicatrización también intervienen células indiferenciadas denominadas "Células troncales mesenquimáticas" (Mesenchymal Stem Cells, MSCs). Estas migran al sitio de la lesión o inflamación, participan en la regeneración del tejido dañado, estimulan la proliferación y diferenciación de las células locales, promueven la recuperación de las células dañadas a través de la secreción de factores de crecimiento y confieren un efecto antiinflamatorio e inmunomodulador ${ }^{3}$ (Figura 1).

Las MSCs se han encontrado en múltiples tejidos principalmente de origen mesodérmico, presentes ahí con el fin de mantener y reparar. Inicialmente descritas por Friedentein et al (1974), desde la médula ósea ${ }^{4}$ (Bone Marrow Mesenchymal Stem Cells, BM-MSCs), luego en el cordón umbilical y últimamente desde el tejido adiposo (Adipose Stem Cells, ASCs $)^{5}$.

Evidencias recientes sugieren que las BM-MSCs participan en la formación de nuevos vasos mediante señales generadas en el tejido dañado ${ }^{6}$, Hamou et al (2009), objetiva que el $24 \%$ de los neovasos generados en un sitio de isquemia se forman a partir de células progenitoras de la médula ósea?

El tejido adiposo se ha identificado como fuente ideal, ya que permite obtener de forma fácil, con mínimo disconfort para el paciente, un gran número de células que pueden ser expandidas en cultivo ${ }^{8}$. Posee la habilidad de cambiar de volumen durante la vida de un individuo, los cambios menores son por hipertrofia celular, pero los cambios mayores se deben a hiperplasia y aumento de la vacularización. Estos cambios están mediados por una población de ACSs con propiedades similares a las obtenidas desde la médula ósea.

El objetivo de esta revisión es describir la técnica que hemos desarrollado para la obtención y cultivo de ACSs desde el tejido adiposo así como una revisión de lo publicado en cuanto a la utilidad clínica en cirugía.

\section{Técnica de obtención y cultivo}

El paciente puede ser anestesiado con anestesia general, regional o local. El tejido adiposo puede ser obtenido por resección quirúrgica, por lipoaspiración tumescente o lipoaspiración ultrasónica. En el caso de la técnica tumescente la infiltración del tejido

Figura 1. Intervención de las células troncales mesenquimáticas en el proceso de cicatrización. Se visualiza su incorporación en el lecho cruento para diferenciación, la secreción de factores de crecimiento y participación en la neoangiogénesis.

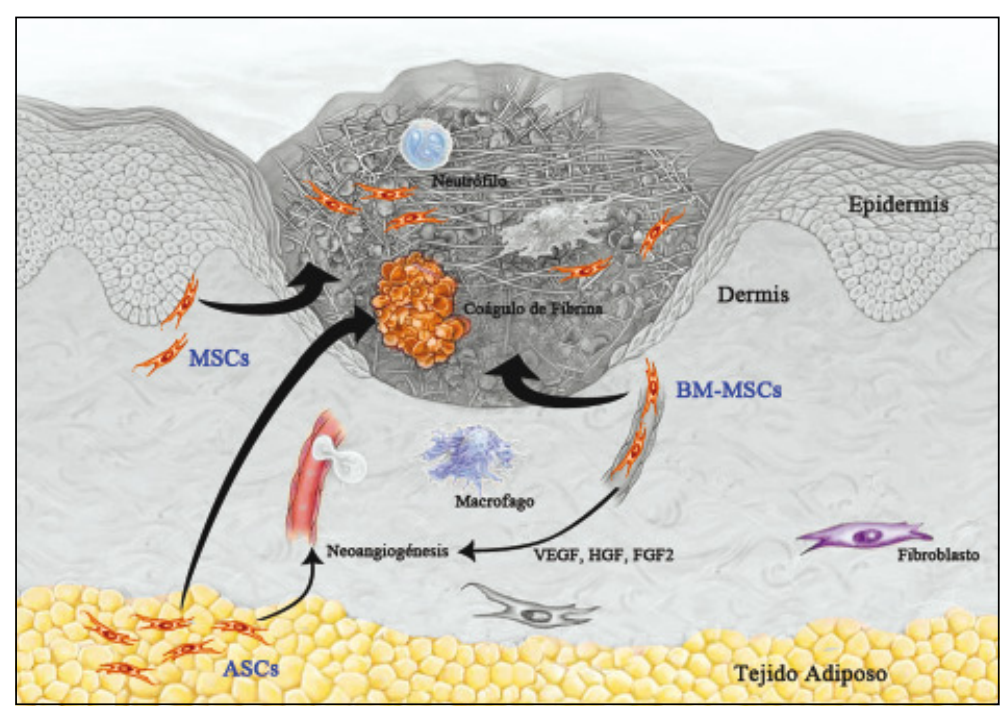




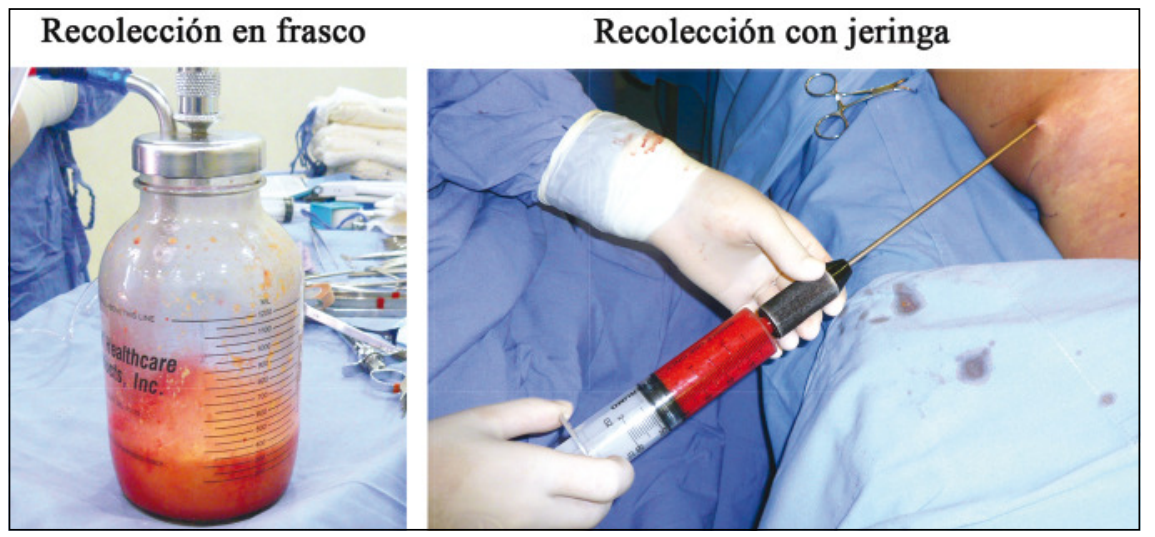

adiposo se realiza con solución fisiológica más epinefrina en concentración de $1 \mathrm{mg} / 1.000 \mathrm{ml}$ y si se requiere además anestesia local la concentración de lidocaína a utilizar es de $400 \mathrm{mg} / 1.000 \mathrm{ml}$.

Las muestras de tejido adiposo son obtenidas mediantes cánulas de lipoaspiración conectadas a presión negativa entre -400 a $-600 \mathrm{mmHg}$ (Figura 2). Este procedimiento genera fragmentos de tejido cuyo tamaño varían dependiendo del grosor de la cánula, se transportan en frascos de $50 \mathrm{cc}$ a $4^{\circ} \mathrm{C}$ hasta su procesamiento según la técnica descrita por Zuk et $\mathrm{al}^{5}$ :

Se lava la muestra con solución buffer-fosfato (PBS) en igual cantidad, agitación, eliminación de las células hemáticas, solución salina y anestésico local, obtención de la fracción estromal. Digestión de la matriz extracelular con Colagenasa II al $0,075 \%$ por 30 minutos a $37^{\circ} \mathrm{C}$. Inactivación de la enzima con igual volumen de medio de cultivo. Centrifugación de la muestra a $1.200 \mathrm{~g}$ por 10 minutos, se obtiene precipitado de alta densidad. El pellet obtenido es resuspendido en medio de cultivo y puesto en placas Falcon ${ }^{\circledR}$ de $100 \mathrm{~mm}$. El medio de cultivo se compone de DMEM $+10 \% \mathrm{FBS}+$ penicilina-estreptomicinaanfotericina B y glutamina $100 \mathrm{UI} / \mathrm{ml}$. Se mantiene a $37^{\circ} \mathrm{C}$ y $5 \%$ de $\mathrm{CO}_{2}$. Se lava a las $24 \mathrm{hrs}$ con PBS para eliminar las células no adherentes al plástico. Se mantiene en el incubador con cambio de medio 2 veces a la semana. Al obtener confluencia $\left(5^{\circ}\right.$ a $7^{\circ}$ día) se realiza tripsinisación para pasar al segundo pasaje (Figura 3).

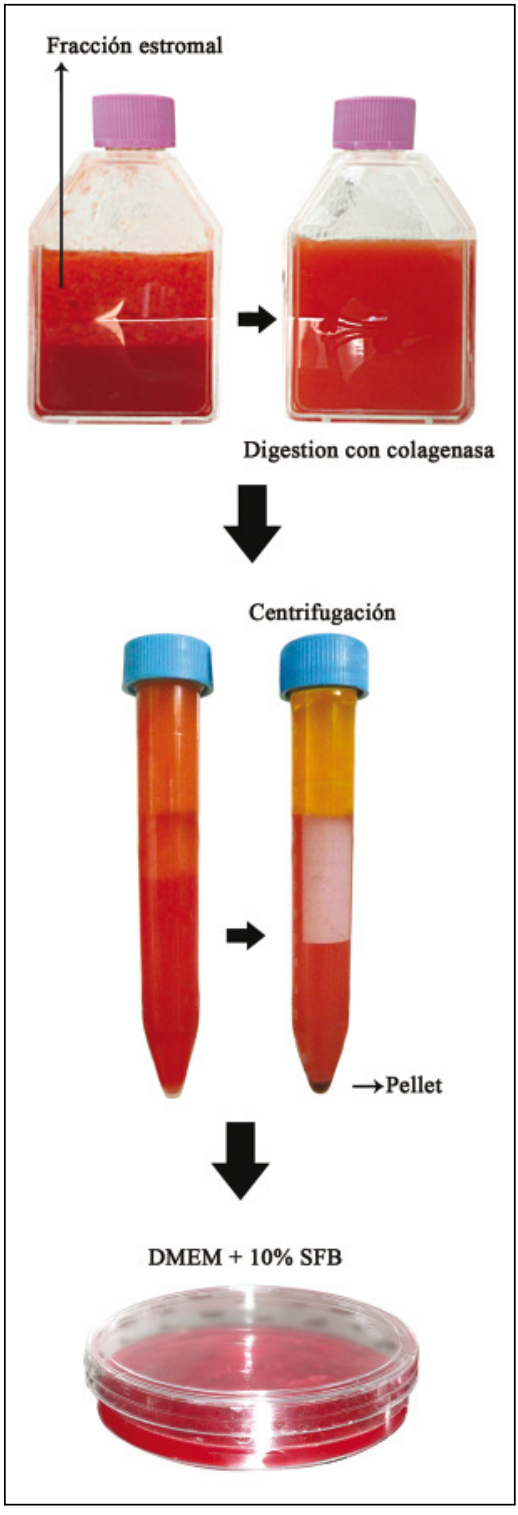

Figura 3. Técnica de obtención de las células troncales. El lipoaspirado se compone de una fracción estromal que es digerida con colagenasa para luego ser centrifugada obteniendo un pellet alto en ASCs que es cultivado. 
El tiempo de doblaje celular es entre 2 a 4 días dependiendo del medio de cultivo y el pasaje en que se encuentre ${ }^{9}$. Si comparamos la capacidad proliferativa, las BM-MSCs llegan hasta el pasaje $\mathrm{N}^{\circ} 15$ mientras las ASCs llegan a sobrepasar el pasaje $\mathrm{N}^{\circ}$ $20^{10}$. Con pasajes prolongados por más de 4 meses, se ha observado que las ASCs pueden ir a la transformación maligna, al menos en 1 reporte se ha demostrado anormalidades cariotípicas con frecuencia mayor a $30 \%$ y cuando son implantadas en una rata inmunodeficiente se forman tumores hasta en $50 \%{ }^{11}$. Estos resultados nos indican que la manipulación de ASCs debe ser con cautela.

\section{Aplicaciones clínicas en cirugía}

\section{Cicatrización cutánea}

Rigotti G et al (2007), trata a 20 pacientes con úlceras en la región torácica secundarias a radioterapia, se inyectó lipoaspirado purificado entre 60 a 120 cc en forma repetida en la zona, con remisión de los síntomas en todos los pacientes, en un seguimiento entre 18 y 33 meses $^{12}$.

\section{Cicatrización en fístulas}

García-Olmo et al, evalúa desde el año 2002 el uso de ASCs para el cierre fístulas en enfermedad de Crohn; en un estudio inicial de fase I evalúa 4 pacientes donde realiza inyección de células en tracto asociado a "pegamento de fibrina", obtiene un éxito de $75 \%$ en cierre con un seguimiento a 22 meses $^{13}$. Posteriormente presenta un estudio aleatorizado con 49 pacientes portadores de fístulas perianales complejas donde evalúa la inyección de "pegamento de fibrina" solo o asociado a ASCs, encontrando un $16 \%$ de cicatrización con el primer tratamiento versus un $71 \%$ con el segundo ${ }^{14}$. Un último reporte del mismo autor nos muestra la efectividad del tratamiento para el cierre de una fístula rectovaginal en enfermedad de Crohn pero esta vez utilizando ASCs de otro paciente dador ${ }^{15}$.

Basados en la primera experiencia se utilizó la misma técnica (pegamento de fibrina más ASCs) para el cierre de una fístula traqueomediastínica secundaria a radioterapia en un paciente con cáncer pulmonar con éxito a los 3 meses de tratamiento ${ }^{16}$.

\section{Aumento de partes blandas}

La combinación de ASCs en conjunto con grasa lipoaspirada autóloga es una técnica denominada CAL (Cell-Assisted-Lipotransfer) descrita por Matsumoto et al (2006) ${ }^{17}$, utilizada para aumentar la supervivencia de la grasa lipoinyectada en al menos un $35 \%$, posteriormente Yoshimura et al $(2008)^{18}$, publica una serie de 40 pacientes a las cuales rea- liza la técnica CAL con éxito y en el año 2009 el mismo autor presenta otra serie de 6 pacientes con lipoatrofia facial donde demuestra la superioridad de la técnica CAL versus la lipoinyección $\sin \mathrm{ASCs}^{19}$.

\section{Regeneración ósea}

Lendeckel et al (2004), publica el caso de una niña de 7 años con un defecto traumático de calota con infección y sin cicatrización por 2 años al cual se le realiza un injerto de cresta ilíaca más ASCs en pegamento de fibrina con osificación casi completa a los 3 meses de tratamiento ${ }^{20}$. Un caso más sorprendente de regeneración ósea ectópica total publica Mesimäki et al (2009), en un caso de una hemimandibulectomía secundaria a un tumor, se realiza la reconstrucción 3 años más tarde con un colgajo microquirúrgico de recto abdominal con ASCs, betatricalcio fosfato y proteína morfogenética de hueso tipo 2, logrando la estructura ósea a los 8 meses, posteriormente se le incluyeron implantes dentales ${ }^{21}$.

\section{Trasplante}

Se ha descrito a las ASCs como inmunoprivilegiadas al carecer del antígeno de histocompatibilidad tipo II y además pueden suprimir la reacción linfocítica mixta, lo que permite que puedan ser trasplantadas alogénicamente y además controlar un rechazo en un trasplante de órgano ${ }^{22}$. Fang et al (2007), realiza inyección endovenosa de ASCs alógenas a 6 pacientes con rechazo agudo de órgano refractario a la terapia con corticoides (grados III-IV), se inyectan $10^{6} / \mathrm{kg}$ células, obteniendo respuesta completa en 5 de los 6 pacientes con sobrevida al seguimiento promedio de 40 meses $^{23}$.

\section{Discusión}

La técnica descrita para la obtención de ASCs en humanos la hemos realizado con éxito, actualmente nos encontramos tipificando estas células y realizando estudios preclínicos de cicatrización en ratas, esperando en un futuro cercano realizar ensayos clínicos en pacientes que lo requieran.

Un hecho fundamental que hay que considerar al momento de manipular estas células para luego ser reintroducidas en un paciente es la contaminación posible de la muestra, no tanto en el procesamiento propiamente tal, sino en el cultivo donde pueden crecer todo tipo gérmenes si no se toman estrictas medidas de esterilidad. Para evitar este potencial inconveniente se pueden ocupar las ASCs frescas sin haber sido cultivadas como lo realizan en el procedimiento de CAL, pero la mayor parte de los autores prefiere el cultivo (expansión) ya que se obtiene una mayor concentración y vitalidad celular. García- 
CÉLULAS TRONCALES DERIVADAS DEL TEJIDO ADIPOSO: TÉCNICA DE OBTENCIÓN Y UTILIDAD EN CIRUGÍA

Tabla 1. Linajes de diferenciación publicados para las ASCs, a la derecha se especifica los medios de cultivos requeridos

\begin{tabular}{ll}
\hline Tipo de diferenciación & Factor inductivo \\
\hline Adiposo & Dexametasona, IBMX, Indometacina, Insulina, Tiazolidona \\
Óseo & Ácido ascórbico, BMP-2, dexametasona, 1,25(OH $)_{2} \mathrm{D}_{3}$ \\
Cartilaginoso & Ácido ascórbico, BMP-6, BMP-7, FGF-2, TGF- $\beta_{1}$, TGF- $\beta_{2}$, TGF- $\beta_{3}$, dexametasona, IGF 1, \\
& insulina \\
Muscular & Dexametasona, suero equino \\
Cardiomuscular & Transferrina, IL-3, IL-6, VEGF \\
Endotelial & Medio especial (EGM-2-MV; Cambrex), Ac. Ascórbico, EGF, bFGF, hidrocortisona \\
Neuronal & Hidroxinisolona, Ácido valproico, Insulina \\
Pancreático & activina-A, exendina-4, HGF, pentagastrina \\
Hepático & HGF, Oncostatina M y dimetil-sulfóxido \\
Epitelial & Ácido trans-retinoico \\
\hline
\end{tabular}

Olmo et al (2009), encuentra que el tratamiento con células expandidas es superior al de células frescas en fístulas ${ }^{24}$.

Es importante mencionar que los beneficios obtenidos con este tipo de terapia celular no sólo se deben a la capacidad de diferenciación de las ASCs en múltiples linajes (Tabla 1), sino que además al ser implantadas en un sitio lesionado liberan citoquinas y factores de crecimiento que estimulan al resto de las células locales de manera paracrina, como el factor de crecimiento vascular endotelial (VEGF), el factor de crecimiento hepatocítico (HGF) y el factor de crecimiento símil a la insulina (IGF-I) ${ }^{25}$, promoviendo de este modo la neoangiogénesis y el reclutamiento de MSCs locales. De similar manera las ASCs proveen antioxidantes y reducción de radicales libres en el sitio isquémico, reduciendo la cantidad de sustancias tóxicas y promoviendo la recuperación de las células locales sobrevivientes ${ }^{8}$.

Si bien algunos estudios de los presentados son sólo reportes de $\operatorname{casos}^{15,16,20,21}$, hay varios que incluyen series $^{12,18,19,22}$ y el grupo de García-Olmo se encuentra realizando estudios randomizados de fase $\mathrm{II}^{14}$. Lo que nos anticipa que esta ya es una terapia disponible.

\section{Conclusión}

El cirujano está directamente involucrado tanto con la obtención como con la utilización de las ASCs, por lo tanto, debe estar al tanto de lo que se ha llevado a cabo en este tema. Si bien los reportes de casos y estudios clínicos son recientes, éstos van a seguir apareciendo asociado al uso progresivo en otras patologías médicas y quirúrgicas, y en un futuro cercano, se definirá en cuales realmente se obtendría el beneficio.

El proceso de cicatrización requiere de células troncales mesenquimáticas tanto locales como del tejido adiposo o de la médula ósea. El acceso al tejido adiposo es mucho más simple a la médula ósea para obtener células troncales y el material que actualmente es desechado en lipoaspiración probablemente será más valioso de lo pensado.

Agradecimientos: A los Drs. Roberto Hoppmann K. y Dante González B. por su colaboración en procedimientos quirúrgicos y al Sr. Simón Saavedra por ilustraciones

\section{Referencias}

1. Elwood D, Pomposelli JJ. Hepatobiliary Surgery: lessons learned from live donor hepatectomy. Surg Clin North Am. 2006;86:1207-17.

2. Singer AJ, Clark RAF. Cutaneous wound healing. N Engl Med. 1999;341:738-46.

3. Hanson SE, Bentz ML, Hematii P. Mesenchymal stem cell therapy for nonhealing cutaneous wounds. Plast Reconst Surg. 2010;125:510-6.

4. Friedenstein AJ, Deriglasova UF, Kulagina NN, Panasuk AF, Rudakowa SF, Luriá EA, et al. Precursors for fibroblasts in different populations of hematopoietic cells as detected by the in vitro colony assay method. Exp Hematol. 1974; 2:83-92.

5. Zuk PA, Zhu M, Mizumo H, Huang J, Futrell W, Katz AJ, et al. Multilineage cells from human adipose tissue: implications for cell-based therapies. Tissue Eng. 2001;7:211-28. 
6. Tepper OM, Capla JM, Galiano R, Ceradini DJ, Callaghan MJ, Kleinman ME, et al. Adult vasculogenesis occurs through in situ recruitment, proliferation, and tubulization of circulating bone marrow-derived cells. Blood. 2005;105:1068-77.

7. Hamou C, Callaghan M, Thangarajah H, Chang E, Chang E. Mesenchymal stem cells can participate in ischemic neovascularization. Plast Reconst Surg. 2009; 123(Suppl): 45S-55S.

8. Gimble J, Katz A, Bunnell B. Adipose-derived stem cells for regenerative medicine. Circulation Research 2007;100:1249-60.

9. Mitchell J, McIntosh K. Inmunophenotype of human adipose-derived cells: temporal changes in stromalassociated stem cell-asociated markers. Stem Cells 2006;24:376-85.

10. Lee RH, Kim B, Choi I, Kim H, Choi HS, Suh KT, et al. Characterization and expression analysis of mesenchymal stem cells from human bone marrow an adipose tissue. Cell Physiol Biochem. 2004;14:311-24.

11. Rubio D, García-Castro J, Martin M, De la Fuente R, Cigudosa J, Lloyd A, et al. Spontaneous human adult stem cell transformation. Cancer Res. 2005;65: 3035-9.

12. Rigotti G, Marchi A, Galié M, Baroni G, Benati D, Krampera M, et al. Clinical treatment of radiotherapy tissue damage by lipoaspirate transplant: a healing process mediated by adipose-derived adult stem cells. Plast Reconst Surg. 2007; 119:1409-22.

13. García-Olmo D, García-Arranz M, Herreros D, Pascual I, Peiro C, Rodríguez-Montes JA. A phase I clinical trial of the treatment of Crohn's fistula by adipose mesenchymal stem cell transplantation. Dis Colon Rectum 2005;48:1416-23.

14. García-Olmo D, Herreros D, Pascual I, Pascual JA, Del Valle E, Zorrilla J, et al. Expanded adipose-derived stem cells for treatment of complex perianal fistula: a phase II clinical trial. Dis Colon Rectum 2009;52:79-86.

15. García-Olmo D, Herreros D, De-La-Quintana P, Guadalajara H, Trébol J, Georgiev-Hristov T, et al. Adiposederived stem cells in Crohn's rectovaginal fistula. Case Reports in Med. 2010; 2010: 961758. Published online 2010 March 7. doi: 10.1155/2010/961758.

16. Díaz-Agero Álvarez P, García-Arranz M, GeorgiervHristov T, García-Olmo D. A new bronchoscopic treatment of tracheomediastinal fistula using autolo- gous adipose-derived stem cells. Thorax 2008;63:3746.

17. Matzumoto D, Sato K, Gonda K, Takaki Y, Shigeura T, Sato T, et al. Cell-Assisted Lipotransfer: supportive use of human adipose-derived cells for soft tissue augmentation with lipoinyection. Tissue Engineering 2006; 12:3375-82.

18. Yoshimura K, Sato K, Aoi N, Kurita M, Hirohi T, Harii K. Cell-assisted lipotransfer for cosmetic breast augmentation: supportive use of adipose-derived stem/ stromal cells. Aesth Plast Surg. 2008;32:48-55.

19. Yoshimura K, Sato K, Aoi N, Kurita M, Inque K. Cellassisted lipotransfer for facial lipoatrophy: efficacy of clinical use of adipose-derived stem cells. Dermatol Surg. 2008;34:1178-85.

20. Lendekel S, Jödicke A, Christophis P, Heidinger K, Wolff J, Fraser JK, et al. Autologous stem cells (adipose) and fibrin glue used to treat widespread traumatic calvarial defects: case report. J Craniomaxillofac Surg. 2004;32:370-3.

21. Mesimäki K, Lindroos B, Törnwall J, Mauno J, Lindqvist $\mathrm{C}$, Kontio R, et al. Novel maxillary reconstruction with ectopic bone formation by GMP adipose stem cells. Int J Maxillofac Surg. 2009;38:201-9.

22. Puissant B, Barreau C, Bourin P, Clavel C, Corre J, Bousquet $\mathrm{C}$, et al. Inmunomodulatory effect of human adipose tissue-derived adult stem cells: comparison with bone marrow mesenchymal stem cells. Br J Haematol. 2005; 129:118-29.

23. Fang B, Song Y, Liao L, Zhang Y, Zhao RC. Favorable response to human adipose tissue-derived mesenchymal stem cells in steroid-refractary acute graft-versushost disease. Transplantation Proceedings 2007;39: 3358-62.

24. García-Olmo D, Herreros D, Pascual M, Pascual I, DeLa-Quintana P, Trebol J, et al. Treatment of enterocutaneous fistula in Crohn's disease with adipose-derived stem cells: a comparison of protocols with and without cell expansion. Int J Colorectal Dis. 2009;24:27-30.

25. Wang M, Crisostomo P, Herring C, Meldrum K, Meldrum D. Human progenitor cells from bone marrow or adipose tissue produce VEGF, HGF and IGF-1 in response to TNF by a p38 mitogen activated protein kinase dependent mechanism. Am J Physiol Regul Integr Comp Physiol. 2006;291:880-4. 